Published in final edited form as:

J Agric Food Chem. 2016 July 13; 64(27): 5607-5613. doi:10.1021/acs.jafc.6b02478.

\title{
Quantification of Toxins in Soapberry (Sapindaceae) Arils: Hypoglycin A and Methylenecyclopropylglycine
}

\author{
Samantha L. Isenberg ${ }^{1}$, Melissa D. Carter ${ }^{2,}$, , Shelby R. Hayes ${ }^{3}$, Leigh Ann Graham ${ }^{1}$, Darryl \\ Johnson $^{3}$, Thomas P. Mathews ${ }^{1}$, Leslie A. Harden ${ }^{4}$, Gary R. Takeoka ${ }^{4}$, Jerry D. Thomas ${ }^{2}$, \\ James L. Pirkle ${ }^{2}$, and Rudolph C. Johnson² \\ ${ }^{1}$ Battelle Memorial Institute at the Centers for Disease Control and Prevention, Atlanta, GA \\ ${ }^{2}$ Division of Laboratory Sciences, National Center for Environmental Health, Centers for Disease \\ Control and Prevention, Atlanta, GA \\ ${ }^{3}$ Oak Ridge Institute for Science and Education Fellow at the Centers for Disease Control and \\ Prevention, Atlanta, GA \\ ${ }^{4}$ Western Regional Research Center, Agricultural Research Service, United States Department of \\ Agriculture Albany, CA
}

\section{Abstract}

\begin{abstract}
Methylenecyclopropylglycine (MCPG) and hypoglycin A (HGA) are naturally-occurring amino acids found in some soapberry fruits. Fatalities have been reported worldwide as a result of HGA ingestion, and exposure to MCPG has been implicated recently in the Asian outbreaks of hypoglycemic encephalopathy. In response to an outbreak linked to soapberry ingestion, the authors developed the first method to simultaneously quantify MCPG and HGA in soapberry fruits from 1 to 10,000 ppm of both toxins in dried fruit aril. Further, this is the first report of HGA in litchi and longan arils. This method is presented to specifically address the laboratory needs of public health investigators in the hypoglycemic encephalitis outbreaks linked to soapberry fruit ingestion.
\end{abstract}

\section{Keywords}

Litchi; lychee; ackee; methylenecyclopropylglycine; hypoglycin A; soapberry; methylenecyclopropylalanine; Acer, Aceraceae; cyclopropylamino acids; Sapindaceae; Aesculus; rambutan

\footnotetext{
*Correspondence to: M.D. Carter, Division of Laboratory Sciences, Centers for Disease Control and Prevention, Atlanta, GA 30341, USA.vsm8@cdc.gov. 770-488-7263.

The manuscript was written through contributions of all authors. All authors have given approval to the final version of the manuscript. Supporting Information

Evaluation of matrix effects, SPE recovery and accuracy and precision for dilution experiments for MCPG and HGA. This material is available free of charge via the Internet at http://pubs.acs.org.

DISCLAIMER

The findings and conclusions in this study are those of the authors and do not necessarily represent the views of the U.S. Department of Health and Human Services, the U.S. Centers for Disease Control and Prevention, or the U.S. Department of Agriculture. Use of trade names and commercial sources is for identification only and does not constitute endorsement by the U.S. Department of Health and Human Services, the U.S. Centers for Disease Control and Prevention, or the U.S. Department of Agriculture.
} 


\section{INTRODUCTION}

Unexplained outbreaks of hypoglycemic encephalopathy have been reported over the past two decades in Asia near litchi-growing regions including India, Bangladesh, and Vietnam. ${ }^{1-6}$ According to a 2013-2014 epidemiologic study, the outbreaks largely affect young children, have greater than a $30 \%$ mortality rate, and coincide with litchi harvesting season. ${ }^{3}$ Initially, these outbreaks were believed to be caused by exposure to an infectious agent or pesticides, but recently a naturally occurring amino acid in litchi fruit was implicated as a causative agent of the illness. ${ }^{2,4-5,7-8}$ Methylenecyclopropylglycine (MCPG) has been reported in both the seeds ${ }^{9-10}$ and edible arils ${ }^{7}$ of litchi fruit and is a lower analogue of hypoglycin A (HGA) which is found in ackee fruit ${ }^{1,11-13}$, another soapberry. HGA is known as the causative agent of Jamaican Vomiting Sickness ${ }^{1,13-18}$ as well as Seasonal Pasture Myopathy ${ }^{19-20}$ and has been more extensively studied than MCPG. A comparison of the individual and additive toxic effects of MCPG and HGA has not been reported, but in rat studies, both were found to be "powerfully hypoglycemic". ${ }^{21}$

In a joint agricultural and public health investigation, the authors developed a clinical method for the identification of soapberry toxin metabolites in humans ${ }^{22}$ and an analytical method for the identification of MCPG and HGA in soapberry fruit. The clinical method was used to evaluate suspected cases of hypoglycemic encephalopathy and confirmed exposure to both MCPG and HGA. ${ }^{22}$ Prior to this publication, only MCPG had been implicated as a causative agent of hypoglycemic encephalopathy. In order to further investigate the cause of hypoglycemic encephalopathy and the source of exposure to MCPG and HGA, an analytical method was developed to quantify MCPG and HGA in edible fruit arils.

Although there are currently agricultural methods for the quantification of HGA in ackee fruit, ${ }^{23-26}$ this is the first method to quantify both MCPG and HGA in fruit arils broadly within the soapberry family. Previous public health studies investigating Jamaican Vomiting Sickness linked HGA content to the ripeness of ackee fruit ${ }^{23}, 26$, leading to a public health action warning against consumption of unripe ackee fruit. The newly developed method will now allow public health investigators to monitor the concentrations of both MCPG and HGA simultaneously with respect to soapberry ripeness, seed size, and cultivar.

When compared to previously published methods, this method offers a number of unique improvements, including broad quantitative detection for both MCPG and HGA in soapberry fruit. Further, the majority of published quantitative methods for the analysis of HGA in ackee fruit use UV detection, and those that employ more specific mass spectrometry detection are burdened by a need for standard addition curves for every sample analyzed. ${ }^{27}$ The HPLC-MS/MS method presented here not only eliminates the need for standard addition curves but also provides a wider quantitative dynamic range (1 to 10,000 $\mu \mathrm{g} / \mathrm{g}$ ) than previously published methods for the quantification of HGA in ackee fruit. ${ }^{25}$ Further, this method is the first reported method to apply dansylation to MCPG quantification and is the first to use isotopically-labeled internal standards for the quantification of HGA or MCPG. 
This work provides a specific HPLC-MS/MS method for the quantification of the toxins MCPG and HGA in soapberry fruit. Of note, the method was developed as part of a public health investigation into hypoglycemic encephalopathy and is not presented as a replacement for current regulatory methods. The portion of the fruit that was of immediate interest was the aril, which is the fleshy, edible portion of the fruit. In this method, the aril of the fruit was dehydrated to normalize for water content between fruits, ${ }^{28}$ which is consistent with recently published methods that desiccated ackee arils prior to analysis. ${ }^{16,27}$ MCPG and HGA were extracted from the dried aril by homogenizing the dried tissue in $80 \%$ ethanol. The toxins in the extract were chemically derivatized and washed by solid-phase extraction prior to analysis by positive mode ESI-HPLC-MS/MS. With the limited information regarding how MCPG concentrations vary, this method can be applied in future academic or pharmaceutical studies of soapberry toxins.

\section{MATERIALS AND METHODS}

\section{Materials}

Initial custom synthesis that led to commercial availability of isotopically-labeled and unlabeled HGA and MCPG standards was contracted from IsoSciences, LLC (King of Prussia, PA). The purity of the unlabeled standards was $297 \%$, and the isotopic incorporation of isotopically-labeled standards was $\geq 99.5 \%$. Label sites for isotopicallylabeled standards are indicated by asterisks in Scheme 1. HPLC grade solvents acetonitrile, methanol and water were obtained from Fisher Scientific (Pittsburgh, PA, USA). Formic Acid (98\% purity) was obtained from Sigma-Aldrich (St. Louis, MO). Dansyl chloride (98\%) was obtained from Fisher Scientific (Pittsburgh, PA, USA). Ethanol ( $299.5 \%$ ) was obtained from Sigma-Aldrich. Sodium hydroxide solution $(0.1 \mathrm{~N})$ was purchased from Sigma-Aldrich. 10x concentrate phosphate buffered saline was purchased from SigmaAldrich. Laboratory deionized (18 M $\Omega$, DI) water was used when specified. Oasis HLB 96well Solid-Phase Extraction plates were obtained from Waters Technologies Corporation (Milford, MA).

\section{Safety Considerations}

MCPG and HGA are known to be hypoglycemic upon ingestion. Appropriate PPE, including safety glasses, gloves and a laboratory coat, should be worn at all times.

\section{Fruit Extraction}

Fruit arils were processed by obtaining a biopsied tissue sample using biopsy forceps (Surgical Tools, Inc. P/N 66.23.10). A photograph of a dissected rambutan (Nephelium lappaceum) is provided in Figure S1, indicating the different fruit components and sampling tools. The fruit sample was then dehydrated at $57{ }^{\circ} \mathrm{C}$ which is the "fruits \& vegetables" setting for one hour, or until dry, using a Nesco FD-75PR Snackmaster Pro Food Dehydrator. Between 1.0 and $3.5 \mathrm{mg}$ of the dried fruit was placed in a $2.0 \mathrm{~mL}$ homogenizer tube pre-filled with $2.8 \mathrm{~mm}$ ceramic beads (P/N 19-628, Omni International, Kennessaw, GA). A $400 \mu \mathrm{L}$ aliquot of 80:20 ethanol:DI water (v:v) was added to each homogenizer tube. The Omni Bead Ruptor 24 Homogenizer was used to homogenize the samples at 4,200 rpm for 1 minute. The homogenate was centrifuged for 10 minutes at 13,200 rpm $(15,800 \times \mathrm{g})$ 
using an Eppendorf centrifuge 5415R. The supernatant was then transferred into a 96 deepwell plate and dried under nitrogen at $60{ }^{\circ} \mathrm{C}$ for 30 minutes. Each well was resuspended with $1 \mathrm{~mL}$ of DI water for every $2 \mathrm{mg}$ of fruit for each sample (2:1 w:v). An analytical flowchart has been provided in Figure $\mathrm{S} 2$.

A $2 \mathrm{mg} / \mathrm{mL}$ rambutan extract was used for the matrix blank. The selection of representative matrices for method intended for application to a broad scope of products is outlined in the FDA guidance document for the validation of chemical methods. ${ }^{29}$ For example, a method to broadly evaluate Pome fruit may include typical representative commodities in the same family, including apples and pears. ${ }^{29}$ Similarly, rambutan was used in this method to serve as a representative matrix for the soapberry family. Using this method, neither MCPG nor HGA were observed in rambutan arils. It should be noted that the rambutan aril extract should be tested for the analytes prior to using a new batch for the matrix blank.

\section{Sample Preparation}

Extracted fruit samples were processed by isotope-dilution with isotopically-labeled calibrators, $\mathrm{MCPG} *\left({ }^{13} \mathrm{C}_{3}-\mathrm{MCPG}\right)$ and $\mathrm{HGA}^{*}\left({ }^{15} \mathrm{~N}^{13} \mathrm{C}_{2}-\mathrm{HGA}\right)$, followed by chemical derivatization with dansyl-chloride and SPE on a Waters HLB 96-well plate. A $10 \mu \mathrm{L}$ aliquot of stock isotopically-labeled calibrator solution (ISTD) at $100 \mathrm{ng} / \mathrm{mL}$ of ${ }^{13} \mathrm{C}_{3}$-MCPG and ${ }^{15} \mathrm{~N}^{13} \mathrm{C}_{2}$-HGA (written henceforth as $\mathrm{MCPG}^{*}$ and $\mathrm{HGA}^{*}$, respectively) was added to each well. For all calibrators, a $25 \mu \mathrm{L}$ aliquot of matrix blank $(2 \mathrm{mg} / \mathrm{mL}$ rambutan extract) was added to a 96 deep-well plate. A $50 \mu \mathrm{L}$ aliquot of stock calibrator solution was added to the appropriate wells. QCs and fruit samples were processed with $25 \mu \mathrm{L}$ of QC or sample extract and $50 \mu \mathrm{L}$ of $18 \mathrm{M} \Omega$ DI water. A $15 \mu \mathrm{L}$ aliquot of $10 \times$ PBS buffer, adjusted to $\mathrm{pH} 11$ with $\mathrm{NaOH}$, was added to each well followed by $50 \mu \mathrm{L}$ of $1 \mathrm{mg} / \mathrm{mL}$ dansyl chloride (dns-Cl) in acetonitrile. ${ }^{27}$ The chemical derivatization was carried out at $60{ }^{\circ} \mathrm{C}$ for 10 minutes to form dns-MCPG, dns-HGA, dns-MCPG* and dns-HGA* (Scheme 1). Following derivatization, $350 \mu \mathrm{L}$ of DI water was added to each well (totaling to $500 \mu \mathrm{L}$ per sample), and the plate was shaken at 1,000 rpm for 30 seconds. Solid-phase extraction (SPE) was carried out using a Waters HLB 96-well SPE plate. Each well was conditioned with $200 \mu \mathrm{L}$ methanol and equilibrated with $200 \mu \mathrm{L}$ 98:2 water:acetonitrile (v:v). The entire $500 \mu \mathrm{L}$ of each derivatized sample were loaded onto the SPE plate and then washed with $200 \mu \mathrm{L} \mathrm{98:2} \mathrm{water:acetonitrile}$ (v:v). The analytes were eluted with $200 \mu \mathrm{L} 2: 98$ water:acetonitrile (v:v) and dried under $\mathrm{N}_{2}$ at $60{ }^{\circ} \mathrm{C}$ for $25 \mathrm{~min}$. The dried samples were resuspended in $50 \mu \mathrm{L}$ of $0.1 \%$ formic acid in DI water.

\section{Preparation of Stock Solutions and QC Materials}

MCPG and HGA were dissolved in DI water to prepare a stock solution of $10 \mu \mathrm{g} / \mathrm{mL}$. The stock solution was diluted with DI water and calibrators 1-8 were dispensed in 20-use aliquots and stored at working stock solutions of $1.00-200 \mathrm{ng} / \mathrm{mL}(7.87 \mathrm{nM}-1.57 \mu \mathrm{M}$ MCPG and $7.08 \mathrm{nM}-1.42 \mu \mathrm{M}$ HGA) at $-70{ }^{\circ} \mathrm{C}$. Isotopically-labeled calibrator solutions were prepared in DI water at $100 \mathrm{ng} / \mathrm{mL}(0.769 \mu \mathrm{M} \mathrm{MCPG} *$ and $0.694 \mu \mathrm{M} \mathrm{HGA} *)$. QC-low, -mid and -high range samples were prepared in a $2 \mathrm{mg} / \mathrm{mL}$ rambutan extract at 7.00, 30.0 and $150 \mathrm{ng} / \mathrm{mL}(0.0551,0.236$, and $1.18 \mu \mathrm{M}$ MCPG and 0.0496, 0.213, and $1.06 \mu \mathrm{M}$ HGA) 
and stored at $-70{ }^{\circ} \mathrm{C}$. QC levels therefore correspond to 3.50, 15.0 and $75.0 \mu \mathrm{g} / \mathrm{gram}$ of dried rambutan.

\section{HPLC-MS/MS}

HGA and MCPG levels in soapberry fruit were determined on an AB Sciex 4000 triple quadrupole instrument (AB Sciex, Framingham, MA, USA) using positive mode ESI. Conventional HPLC elution was performed using an Agilent 1260 Infinity series HPLC system (Agilent, Santa Clara, CA, USA). Samples were injected at $2.5 \mu \mathrm{L}$ volumes onto an Agilent Zorbax SB-C18 Rapid Resolution HT column $(2.1 \times 50 \mathrm{~mm}, 1.8 \mu \mathrm{m})$ equipped with an Agilent low-dispersion in-line filter ( $2 \mu \mathrm{m}$ frit). Column and autosampler tray temperatures were $60{ }^{\circ} \mathrm{C}$ and $5{ }^{\circ} \mathrm{C}$, respectively. Mobile phases consisted of $0.1 \%$ formic acid in HPLC grade (A) water and (B) acetonitrile. A gradient was delivered at $500 \mu \mathrm{L} / \mathrm{min}$ with an average back pressure of 320 bar, starting from $10 \%$ B for 0.10 min. From 0.10 to $2.50 \mathrm{~min}$, mobile phase B was increased linearly from $10 \%$ to $70 \%$, followed by an equilibration of the chromatography column at $10 \% \mathrm{~B}$ for $1.49 \mathrm{~min}$. The following optimized instrument parameters were applied for the detection of the analytes: collision gas at $7 \mathrm{psig}$; curtain gas at $10 \mathrm{psig}$; ion source gas 1 at $60 \mathrm{psig}$; ion source gas 2 at $60 \mathrm{psig}$; ion spray voltage at $4500 \mathrm{~V}$; temperature at $500{ }^{\circ} \mathrm{C}$; collision exit potential at $5.0 \mathrm{~V}$; dwell time at $75.0 \mathrm{~ms}$; and a 'unit' resolution of $0.7 \mathrm{amu}$ at full width half max. Quantitation was determined by MRM (dns-MCPG quantitation ion $\mathrm{m} / \mathrm{z} 361.1 \rightarrow 170.1$, collision energy of $29 \mathrm{~V}$; dns-MCPG confirmation ion $\mathrm{m} / z 361.1 \rightarrow 157.1$, collision energy of $39 \mathrm{~V}$; dns$\mathrm{MCPG}^{*} \mathrm{~m} / \mathrm{z} 364.1 \rightarrow 157.1$, collision energy of $39 \mathrm{~V}$; dns-HGA quantitation ion $\mathrm{m} / \mathrm{z} 375.1$ $\rightarrow 170.1$, collision energy of $27 \mathrm{~V}$; dns-HGA confirmation ion $\mathrm{m} / \mathrm{z} 375.1 \rightarrow 157.1$, collision energy of $39 \mathrm{~V}$; dns-HGA* $\mathrm{m} / \mathrm{z} 378.1 .1 \rightarrow 170.1$, collision energy of $27 \mathrm{~V}$ ) in ESI positive ion mode (Figure 1). The declustering potential was $45 \mathrm{~V}$ and the entrance potential was $8.0 \mathrm{~V}$ for dns-MCPG and dns-MCPG*. For dns-HGA and dns-HGA*, the declustering potential was $40 \mathrm{~V}$ and the entrance potential was $12 \mathrm{~V}$. The product ion spectra for both analytes are provided in Figure 1.

\section{High Resolution Mass Spectrometry}

High-resolution product ion spectra were acquired on a Thermo Scientific Q Exactive HF hybrid quadrupole-Orbitrap mass spectrometer. MS/MS HCD fragmentation was carried out at $35 \mathrm{NCE}$, with a resolution of 30,000 and an isolation width of $1.5 \mathrm{~m} / \mathrm{z}$.

\section{Data Acquisition and Processing}

Data acquisition and quantitative spectral analysis were carried out utilizing AB Sciex Analyst v.1.6 build 3773. Percent relative error was reported as $\% R E=\left[\left(C_{e}-C_{t}\right) / C_{t}\right] \times 100$ where $C_{e}$ is the experimental concentration determined from the calibration curve slope, and $C_{t}$ is the theoretical concentration. The percent relative standard deviation $\% R S D=(S D /$ $\left.C_{a v g}\right) \times 100$ was calculated as a measure of assay precision, where $C_{a v g}$ is the average concentration calculated, and $S D$ is the standard deviation. Peak area ratios of dns-MCPG/ dns-MCPG* and dns-HGA/dns-HGA* were plotted as a function of theoretical concentration to construct calibration curves of a series of eight calibrators in rambutan aril extract. Each calibrator was injected $(n=22)$ and validated over the concentration range of $1.00-200 \mathrm{ng} / \mathrm{mL}$. QCs in rambutan extract were made up at 75.0, 15.0, and $3.5 \mu \mathrm{g} / \mathrm{g}$ dried 
rambutan and injected alongside calibrators. QC characterization ( $n=22)$ was completed over the course of nine weeks, with three analysts participating and no more than two curves run per day. ${ }^{30}$ The acceptable QC range of each analyte for the optimized method parameters were determined from the QC characterization, as defined by the Centers for Disease Control and Prevention's (CDC) multi-rule quality control system (MRQCS). ${ }^{30}$

\section{Results Reporting}

Following the above extraction procedure, the $2 \mathrm{mg} / \mathrm{mL}$ fruit extracts were processed such that there was a 1:2 dilution, and the final concentration of fruit in the injected solution was $1 \mathrm{mg} / \mathrm{mL}$. The concentration of each analyte was quantified in units of $\mathrm{ng} / \mathrm{mL}$ by the quantitation software. Therefore, the concentration of the analyte in fruit can be readily converted to $\mu \mathrm{g} / \mathrm{g}$ of dried fruit using the following equation:

$$
\frac{n g \text { analyte }}{m L \text { solution }} \times \frac{m L \quad \text { solution }}{m g \text { fruit }}=\frac{n g \text { analyte }}{m g \text { fruit }}=\frac{\mu g \text { analyte }}{g \text { fruit }}=p p m \text { analyte in fruit }
$$

\section{Application Sample Set}

Five rambutan (Nephelium lappaceum), five longan (Dimocarpus longan), one ackee (Blighia sapida) and eighteen litchi (Litchi chinensis) that were purchased commercially in the United States were analyzed for both MCPG and HGA. Additionally, canned longan, lychee and rambutan fruit obtained in the United States were analyzed for both MCPG and HGA. Samples for which laboratory analysis was requested during a hypoglycemic encephalopathy outbreak included six separate litchi aril homogenates, each consisting of six individual litchi fruit.

\section{RESULTS AND DISCUSSION}

\section{Soapberry Aril Extraction}

Representative samples from soapberry arils were obtained using biopsy forceps. The fruit was dehydrated prior to homogenization or blending to normalize for water content between fruits and prevent bias from to moisture loss during blending. ${ }^{28}$ The fruit extraction was validated by assessing changes in the following parameters: percent ethanol in extraction solvent, homogenization time, and centrifugation time. Each parameter was evaluated at a higher level and a lower level than the final method $(n=4)$. For example, the percent ethanol in the extraction solvent, $80 \%$, was also evaluated at $60 \%$ and $100 \%$. These experiments were carried out with one individual litchi fruit that had previously tested positive for both analytes. A summary of the data obtained from these experiments is included in the supplemental Figure S3. When these extraction parameters were varied, the MCPG and HGA concentrations remained within two standard deviations of the values obtained with the final validated method, except when the centrifugation time was increased to 15 minutes, the concentration of MCPG was within three standard deviations of the value obtained with the final validated method.

The ruggedness of the fruit sampling method was also tested to determine if one biopsy sample from the aril would be sufficient to test an individual fruit aril. Six biopsied tissues 
were taken from one fruit for comparison. Additionally, two samples, approximately two grams each, were taken from the same fruit and homogenized prior to dehydration. Each biopsied tissue and both of the homogenized samples were processed by the same method. The resulting concentrations for each condition are provided in Table 1 . The \%RSD was found to be $\leq 10 \%$ for MCPG and $\leq 13 \%$ for HGA.

\section{Detection and Separation}

Under the gradient reversed-phase HPLC conditions previously described, dns-MCPG and dns-HGA were retained chromatographically for 2.58 and 2.75 minutes, respectively. Matrix effects were evaluated by making an injection of $1.00 \mathrm{mg} / \mathrm{mL}$ fruit extract while infusing dns-MCPG and dns-HGA. ${ }^{31}$ Matrix effects were not observed for either analyte (Figure S4). The peak signal intensity of the lowest calibrator $(1.00 \mathrm{ng} / \mathrm{mL})$ was at least 3 -fold higher than the matrix blank (Figure 2). The highest reportable limit (HRL) for the method is defined as the highest calibrator, $200 \mathrm{ng} / \mathrm{mL}$. The theoretical LOD as determined by the Taylor method ${ }^{32}$ is $0.748 \mathrm{ng} / \mathrm{mL}$ for MCPG and $0.628 \mathrm{ng} / \mathrm{mL}$ HGA. The experimental LOD or lowest reportable limit (LRL) for the method is defined as the lowest calibrator, 1.00 $\mathrm{ng} / \mathrm{mL}$ for both MCPG and HGA. The LRL corresponds to an on-column mass of $2.5 \mathrm{pg}$ based on a $2.5 \mu \mathrm{L}$ injection volume.

\section{Linearity, Precision and Accuracy}

The peak area ratios of dns-MCPG and dns-HGA to their respective internal calibrators were linearly proportional to the expected concentration from 1.00 to $200 \mathrm{ng} / \mathrm{mL}$. Over this linear range, the average $(n=22)$ coefficient of determination, $R^{2}$ was $0.9993 \pm 0.0006$ for MCPG and $0.9985 \pm 0.0011$ for HGA. The corresponding line equations were $y=(0.038 \pm 0.002) x$ $-(0.003 \pm 0.012)$ and $y=(0.084 \pm 0.003) x+(0.006 \pm 0.012)$, respectively. The method accuracy and precision values shown in Table 2 for MCPG and HGA were determined by calculating the \%RE (percent relative error) and \%RSD (percent relative standard deviation) of 22 separate measurements over a 9 week period. Three analysts participated in the method validation, analyzing no more than two calibration curves and corresponding QCs per day. A low-, mid-, and high-level QC was used for each analyte covering the calibration range. For MCPG, low-, mid- and high-level QCs demonstrated \%REs $\leq 12 \%, \leq 5.8 \%$, and $\leq 1.5 \%$, with corresponding $\%$ RSDs of $\leq 12 \%, \leq 6.3 \%$, and $\leq 8.8 \%$, respectively. The \%RE observed for HGA QCs was $\leq 6.6 \%, \leq 13 \%$, and $\leq 3.1 \%$, with corresponding \%RSDs of $\leq$ $7.8 \%, \leq 7.8 \%$, and $\leq 8.6 \%$. These precision and accuracy measurements include intraday instrument variability, variations in preparation by multiple analysts, multiple SPE sorbent lots, and multiple chromatographic column lots. The variability inherent in the provided precision values and the acceptability starting point guidelines provided in the FDA guidance document allow for acceptable precision and accuracy up to $16 \% .{ }^{29}$

\section{Stability}

The stability of HGA and MCPG in fruit extract was evaluated by allowing the QC materials ( $n=3$ for $\mathrm{QH}, \mathrm{QM}$, and QL) to stand for 4,8 and 24 hours at 4 and $22{ }^{\circ} \mathrm{C}$ prior to the addition of ISTD. At $4{ }^{\circ} \mathrm{C}$, all QC materials remained within $7 \%$ of the initial value up to 24 hours. All QC materials remained within $13 \%$ of the initial value up to 24 hours when stored at $22{ }^{\circ} \mathrm{C}$. The stability of the QC materials at room temperature is important in the event that 
the materials are left on the benchtop for several hours. At $60{ }^{\circ} \mathrm{C}$, all QCs were evaluated for 1,2 , and 4 hours ( $n=3$ for $\mathrm{QH}, \mathrm{QM}$, and QL) to evaluate analyte stability during fruit dehydration and the extract dry-down steps. All QC materials remained within $11 \%$ of the initial value up to 4 hours when stored at $60{ }^{\circ} \mathrm{C}$. Storage effects were also assessed by determining the measured QC concentrations after 20 freeze-thaw cycles from -70 to $25^{\circ} \mathrm{C}$. QC materials were evaluated after 1,2, 5, 10, and 20 freeze-thaw cycles and remained within $13 \%$ of the initial value. All QC materials were found to be stable under the tested conditions within the acceptable characterized values as determined by the MRQCS. It is recommended that the standards and QCs be stored at $-20^{\circ} \mathrm{C}$ or less, but based on stability at $22{ }^{\circ} \mathrm{C}$, the solutions may be left on the benchtop for at least 24 hours prior to sample preparation.

\section{Analytical Ruggedness}

The analytical ruggedness of the method was tested by assessing the changes in the following parameters: LC column temperature, injection volume, LC flow rate, multiple SPE sorbent lots, and multiple column lots. The ruggedness of the method was evaluated by comparing the calculated quality control concentration at the adjusted parameter to its calculated concentration obtained from the optimized method parameters. Each parameter was evaluated at a higher level and a lower level than the final method. For example, the flow rate, $500 \mu \mathrm{L} / \mathrm{min}$, was also evaluated at 400 and $600 \mu \mathrm{L} / \mathrm{min}$. For all ruggedness testing, the measured $\mathrm{QC}$ values were within the two standard deviation range determined during QC characterization. ${ }^{30}$

\section{SPE Recovery}

SPE recovery was determined for both analytes. Standards 1, 5, and 8 (1.00, 20.0, and 200 $\mathrm{ng} / \mathrm{mL})$ were processed in rambutan extract. The peak areas obtained with SPE $(\mathrm{n}=4)$ were compared to those obtained without SPE $(\mathrm{n}=4)$ and are provided in Table S1. The percent recovery was $\mathbf{2 5 0 \%}$ for both analytes. Although analyte losses occur during SPE, the loss is normalized by isotope dilution across the linear range. During method development, SPE was necessary because when the soapberry extracts were analyzed without SPE, the ion source of the mass spectrometer became noticeably dirty. Due to the need for this method to provide high-throughput analysis of a potentially large number of samples, SPE was used for sample cleanup.

\section{Dilution of samples}

If a sample has an experimental concentration that exceeds the highest reportable limit for the method, it should be diluted with DI water to be quantified within the linear range. To determine if dilution would provide accurate results for extracts exceeding $200 \mathrm{ng} / \mathrm{mL}$ analyte, fruit extracts were prepared at $1.00,5.00$, and $10.0 \mathrm{mg}$ toxin/g of fruit. Following the extraction procedure without dilution, these samples would have final concentrations of $1.00,5.00$, and $10.0 \mu \mathrm{g} / \mathrm{mL}$, exceeding the HRL of the method. These extracts were diluted by a factor of 50 prior to the addition of the internal calibrator solution such that the final diluted extract was $20.0,100$, and $200 \mathrm{ng} / \mathrm{mL}$ in $20 \mu \mathrm{g} / \mathrm{mL}$ fruit extract. Results of the dilution experiments are given in Tables S2 and S3. The concentrations in fruit given in $\mathrm{mg} / \mathrm{g}$ in Tables S2 and S3 were determined using the equation shown in the "results 
reporting" section earlier. The $\% \mathrm{RE}$ and $\% \mathrm{RSD}$ were $\leq 10 \%$, indicating that the accuracy and precision of the method remains acceptable for the dilution of samples up to at least 10 $\mathrm{mg} / \mathrm{g}$. The dilution of high-concentration samples allows the method to span a range of 4 orders of magnitude from $1.00 \mu \mathrm{g} / \mathrm{g}$ up to $1.00 \times 10^{4} \mu \mathrm{g} / \mathrm{g}$ MCPG and HGA in dried fruit. The ability to span a wide quantitative range is desirable so that this method may be used to investigate the changes in the toxin concentrations as a function of fruit ripeness, seed size, and cultivar. In ackee fruit, the concentration of HGA is known to vary by several orders of magnitude as a function of fruit ripeness, ${ }^{23,26}$ and it is feasible other soapberry fruits may exhibit similar concentration variations of HGA and/or MCPG.

\section{Application of the Method}

This method was applied to twenty-four individual fruits: five rambutans (Nephelium lappaceum), eighteen litchis (Litchi chinensis), five longans (Dimocarpus longan) and one ackee (Blighia sapida) (Table 3). For a rambutan convenience set of five fruit, both analytes were below the $1 \mu \mathrm{g} / \mathrm{g}$ LRL for all five fruit arils. Of eighteen litchi fruit obtained commercially (six fruit tested from three different vendors), seven were below the LRL for MCPG, and one was below the LRL for hypoglycin A. In the fruit that were above the method LRL, $1.00 \mu \mathrm{g} / \mathrm{g}$, concentrations of MCPG in the litchi arils ranged from 1.35 to 9.73 $\mu \mathrm{g} / \mathrm{g}$ dried fruit, and HGA concentrations ranged from 1.00 to $21.2 \mu \mathrm{g} / \mathrm{g}$ dried fruit. The five longan arils were below the LRL for MCPG, and two were below the LRL for HGA. Three of the longan fruit contained measurable amounts of HGA that ranged from 1.08 to 2.45 $\mu \mathrm{g} / \mathrm{g}$. Additionally, an isomer of HGA was observed in the longan extract that, when dansylated, was chromatographically baseline-resolved from dns-HGA. This isomer, 2amino-4-methylhex-5-ynoic acid, was previously reported in longan seeds by H. Minakata et. al., ${ }^{10}$ and a high-resolution product ion spectra of the derivatized isomer in the longan aril extract is provided in Figure S5. An aril from an ackee fruit was found to contain $1.07 \mu \mathrm{g} / \mathrm{g}$ of HGA, but was below the LRL for MCPG. In canned fruit, MCPG and HGA were below the method's LRL in both rambutan and longan. In the canned litchi, MCPG was below the LRL and HGA was found at a concentration of $1.41 \mu \mathrm{g} / \mathrm{g}$. The method was further applied in a laboratory technical assist to analyze litchi fruit obtained during a public health investigation of hypoglycemic encephalopathy. Observed levels ranged from 44.9 to 220 $\mu \mathrm{g} / \mathrm{g}$ of MCPG and 12.4 to $152 \mu \mathrm{g} / \mathrm{g}$ of HGA in the homogenate litchi samples provided.

MCPG and HGA have been reported previously in litchi seeds ${ }^{7,9-10}$, and MCPG has been reported in litchi arils, ${ }^{7}$ but this is the first report of HGA in the arils of litchi fruit. Similarly, HGA and 2-amino-4-methylhex-5-ynoic acid had been previously reported in longan seeds,${ }^{10}$ but this is the first report of both the compounds in the edible aril portion of the longan fruit. This method has been broadly developed for the analysis of soapberry fruits suspected to contain MCPG and/or HGA. Further, the instrumentation used to develop this method is identical to the instrumentation used in the previously reported clinical method used to detect urinary metabolites of MCPG and HGA, ${ }^{22}$ allowing the analyses to be carried out on a single platform. This method may also be adapted to quantify MCPG and HGA in seeds, such as the box elder seeds known to cause seasonal pasture myopathy in horses, and the clinical method may be adapted to detect urinary metabolites of MCPG and HGA in horses. ${ }^{19-20}$ The method presented herein can be applied to study varying stages of unripe 
and ripe soapberry fruit, different soapberry cultivars, and further expanded to evaluate additional isomers of hypoglycins. Evaluating the concentrations of toxins in fruit is integral in the detection and prevention of associated outbreaks that have been linked to soapberry ingestion.

\title{
Supplementary Material
}

Refer to Web version on PubMed Central for supplementary material.

\section{ACKNOWLEDGMENT}

The authors would like to acknowledge Scott Landvatter and Rich Tyburski for their efforts towards the initial custom synthesis that led to the commercial availability of the standards and isotopically-labeled internal standards that were imperative for this work.

Funding Sources

This work was supported by the Centers for Disease Control and Prevention, the Battelle Memorial Institute, the Oak Ridge Institute for Science and Education, and the U.S. Department of Agriculture.

\section{ABBREVIATIONS}

\author{
$\mathbf{C}_{\text {avg }}$ \\ average concentration \\ $\mathbf{C}_{\mathbf{e}}$ \\ experimental concentration \\ $\mathbf{C}_{\mathbf{t}}$ \\ theoretical concentration \\ CDC \\ Centers for Disease Control and Prevention \\ dns-Cl \\ dansyl chloride \\ dns-HGA \\ dansyl-hypoglycin A \\ dns-HGA* \\ dansyl- ${ }^{15} \mathrm{~N}^{13} \mathrm{C}_{2}$-hypoglycin $\mathrm{A}$ \\ dns-MCPG \\ dansyl-methylenecyclopropylglycine \\ dns-MCPG* \\ dansyl- ${ }^{13} \mathrm{C}_{3}$-methylenecyclopropylglycine \\ DI \\ deionized \\ ESI \\ electrospray ionization \\ FDA \\ U.S. Food and Drug Administration \\ HGA \\ hypoglycin A \\ HGA* \\ ${ }^{15} \mathrm{~N}^{13} \mathrm{C}_{2}$-hypoglycin A
}

HPLC-MS/MS

high-pressure liquid chromatography-tandem mass spectrometry

HRL

highest reportable limit 


$\begin{array}{ll}\text { ISTD } & \text { isotopically-labeled calibrator solution } \\ \text { JVS } & \text { Jamaican Vomiting Sickness } \\ \text { LOD } & \text { limit of detection } \\ \text { LRL } & \text { lowest reportable limit } \\ \text { MCPG } & \text { methylenecyclopropylglycine } \\ \text { MCPG* } & { }^{13} \mathrm{C}_{3} \text {-methylenecyclopropylglycine } \\ \text { MRM } & \text { multiple reaction monitoring } \\ \text { MRQCS } & \text { multi-rule quality control system } \\ \text { PPE } & \text { personal protective equipment } \\ \text { QC } & \text { quality control } \\ \text { \%RE } & \text { percent relative error } \\ \text { \%RSD } & \text { percent relative standard deviation } \\ \text { SD } & \text { standard deviation } \\ \text { SPE } & \text { solid-phase extraction }\end{array}$

\section{References}

1. Tanaka K, Ikeda Y. Hypoglycin and Jamaican Vomiting Sickness. Prog. Clin. Biol. Res. 1990; 321:167-184. [PubMed: 2183231]

2. John TJ, Das M. Acute Encephalitis Syndrome in children in Muzaffarpur: Hypothesis of toxic origin. Curr. Sci. India. 2014; 106:1184-1185.

3. Shrivastava A, Srikantiah P, Kumar A, Bhushan G, Goel K, Kumar S, Kumar T, Mohankumar R, Pandey R, Pathan P, Tulsian Y, Pappanna M, Pasi A, Pradhan A, Singh P, Somashekar D, Velayudhan A, Yadav R, Chhabra M, Mittal V, Khare S, Sejvar JJ, Dwivedi M, Laserson K, Earhart KC, Sivaperumal P, Kumar AR, Chakrabarti A, Thomas J, Schier J, Signh R, Shankar RS, Dhariwal AC, Chauhan LS. Outbreaks of unexplained neurologic illness - Muzaffarpur, India, 2013-2014. MMWR. 2015; 64:49-53. [PubMed: 25632950]

4. Pulla P. A child-killing toxin emerges from shadows: Scientists link mystery deaths in India to consumption of lychees. Science. 2015; 348:15-16. [PubMed: 25838358]

5. Yadav, R. Outbreak of acute neurologic illness outbreak, Muzaffarpur, Bihar, India, 2014; 64th Annual Epidemic Intelligence Service Conference; Centers for Disease Control and Prevention: Atlanta, GA. 2015; Centers for Disease Control and Prevention: Atlanta, GA

6. Paireau J, Tuan NH, Lefrancois R, Buckwalter MR, Nghia ND, Hien NT, Lortholary O, Poiree S, Manuguerra J, Gessian A, Albert ML, Brey PT, Nga PT, Fontanet A. Litchi-associated acute encephalitis in children, Northern Vietnam, 2004-2009. Emerg. Infect. Dis. 2012; 18:1817-1824. [PubMed: 23092599]

7. Das M, Athana S, Singh SP, Dixit S, Tripathi A, John TJ. Litchi fruit contains methylene cyclopropyl-glycine. Curr. Sci. India. 2015; 109:2195-2197.

8. Spencer PS, Palmer VS, Mazumder R. Probably toxic cause for suspected lychee-linked viral encephalitis [letter]. Emerg. Infect. Dis. 2014; 21:904-905.

9. Gray DO, Fowden L. a-(Methylenecyclopropyl)glycine from litchi seeds. Biochem. J. 1962; 173:356-357. 
10. Minakata H, Komura H, Tamura SY, Ohfune Y, Nakanishi K, Kada T. Antimutagenic unusual amino acids from plants. Experientia. 1985; 41:1622-1623. [PubMed: 3935481]

11. Hassall CH, Reyle K, Feng P. Hypoglycin A, B: Biologically active polypeptides from Blighia sapida. Nature. 1954; 173:356-357.

12. Hassall CH, R. K. Hypoglycin A and B, two biologically active polypeptides from Blighia sapida. Biochem. J. 1955; 60:334-339. [PubMed: 14389244]

13. Sherratt HSA. Hypoglycin, the famous toxin of the unripe Jamaican ackee fruit. Trends Pharmacol. Sci. 1986; 7:186-191.

14. McTague JA. Jamaican Vomiting Sickness in Toledo, Ohio. Ann. Emerg. Med. 1994; 23:11161118. [PubMed: 8185109]

15. Tanaka K, Kean EA, Johnson B. Jamaican Vomiting Sickness: Biochemical investigation of two cases. New Engl. J. Med. 1976; 295:461-467. [PubMed: 940578]

16. Gaillard Y, Carlier J, Berscht M, Mazoyer C, Bevalot F, Guitton J, Fanton L. Fatal intoxication due to ackee (Blighia sapida) in Suriname and French Guyana. GC-MS detection and quantification of Hypoglycin-A. Forensic Sci. Int. 2011; 206:e103-e107. [PubMed: 21324617]

17. Joskow R, Belson M, Vesper H, Backer L, Rubin C. Ackee fruit poisoning: An outbreak investigation in Haiti 2000-2001, and review of the literature. Clin. Toxicol. 2006; 44:267-273.

18. Henry SH, Page SW, Bolger PM. Hazard assessment of ackee fruit (Blighia sapida). Human Ecol. Risk Assess. 1998; 4:1174-1187.

19. Bochnia M, Ziegler J, Sander J, Uhlig A, Schaefer S, Vollstedt S, Glatter M, Abel S, Recknagel S, Schusser GF, Wensch-Dorendorf M, Zeyner A. Hypoglycin A Content in Blood and Urine Discriminates Horses with Atypical Myopathy from Clinically Normal Horses Grazing on the Same Pasture. PLoS ONE. 2015; 10(9):e0136785. [PubMed: 26378918]

20. Valberg SJ, Sponseller BT, Hegeman AD, Earing J, Bender JB, Martinson KL, Patterson SE, Sweetman L. Seasonal Pasture Myopathy/Atypical Myopathy in North America associated with ingestion of hypoglycin A within seeds of the box elder tree. Equine Vet. J. 2012:1-8.

21. Melde K, Jackson S, Bartlett K, Sherratt SA, Ghisla S. Metabolic consequences of methylenecyclopropylglycine poisoning in rats. Biochem. J. 1991; 274:395-400. [PubMed: 2006907]

22. Isenberg SL, Carter MD, Graham LA, Mathews TP, Johnson D, Thomas JD, Pirkle JL, Johnson RC. Quantification of metabolites for assessing human exposure to soapberry toxins hypoglycin A and methylenecyclopropylglycine. Chem. Res. Toxicol. 2015; 28:1753-1759. [PubMed: 26328472]

23. Bowen-Forbes CS, Minott DA. Tracking hypoglycins A and B over different maturity stages: Implications for detoxification of ackee (Blighia sapida K.D. Koenig Fruits). J. Agr. Food Chem. 2011; 59:3869-3875. [PubMed: 21410289]

24. Dundee SJS, Minott DA. Impact of seed size on residual hypoglycin levels in ackee. Food Res. Int. 2012; 47:306-309.

25. Ware G. Method validation study of hypoglycin A determination in ackee fruit. J. AOAC Int. 2002; 85:933-937. [PubMed: 12180690]

26. Brown M, Bates RP, McGowan C, Cornell JA. Influence of fruit maturity on the Hypoglycin A level in ackee (Blighia Sapida). J. Food Safety. 1991; 12:167-177.

27. Carlier J, Guitton J, Moreau C, Boyer B, Bevalot F, Fanton L, Habyarimana J, Gault G, Gaillard Y. A validated method for quantifying hypoglycin A in whole blood by UHPLC-HRMS/MS. J. Chromatogr. B. 2015; 978-979:70-77.

28. Curren, MSS.; King, JW. Comprehensive Analytical Chemistry. Vol. 37. Elsevier; 2002. Chapter 25 Sampling and sample preparation for food analysis; p. 869-894.

29. FDA, US Food and Drug Administration. Office of Foods and Veterinary Medicine. Guidelines for the Validation of Chemical Methods for the FDA FVM Program. 2015.

30. Caudill SP, Schleicher RL, Pirkle JL. Multi-Rule quality for the age-related eye disease study. Statist. Med. 2008; 27:4094-4106.

31. Annesley TM. Ion suppression in mass spectrometry. Clin. Chem. 2003; 7:1041-1044.

32. Taylor, JK. Quality Assurance of Chemical Measurements. CRC Press; Boca Raton, FL: 1987. 
(A) 10000

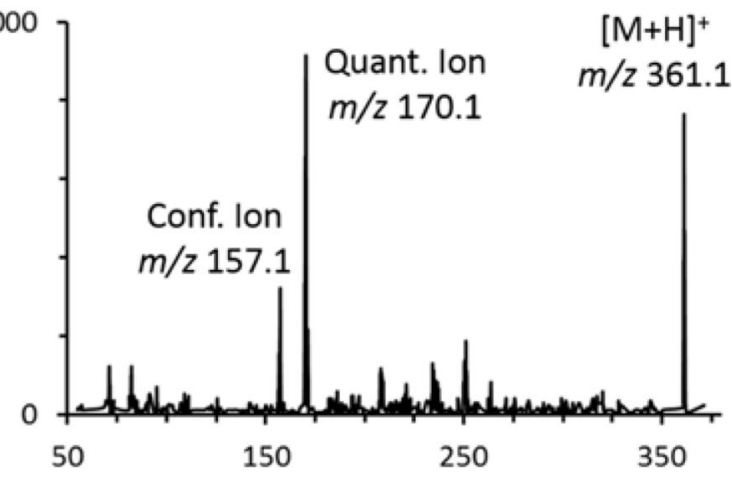

(B)

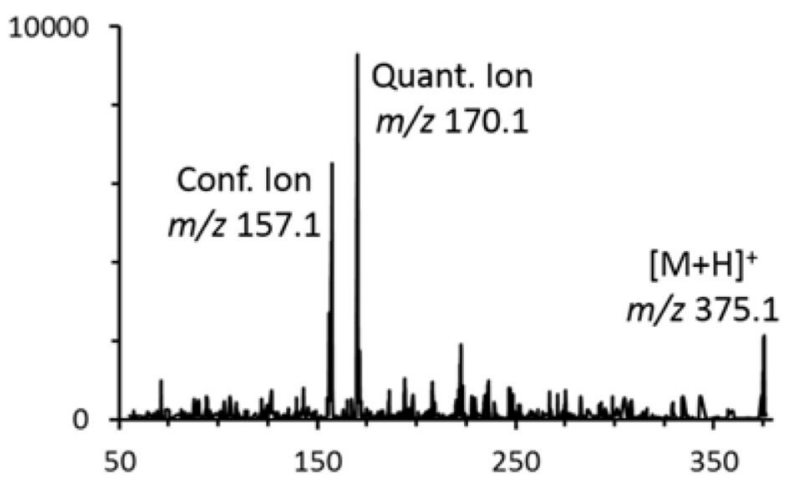

Figure 1.

Representative product ion mass spectra for (A) dns-MCPG and (B) dns-HGA. Both parent ions $(\mathrm{m} / \mathrm{z} 361.1$ and 375.1 , respectively) dissociate to product ions at $\mathrm{m} / \mathrm{z} 170.1$ (quantitation ion) and $\mathrm{m} / \mathrm{z} 157.1$ (confirmation ion). 

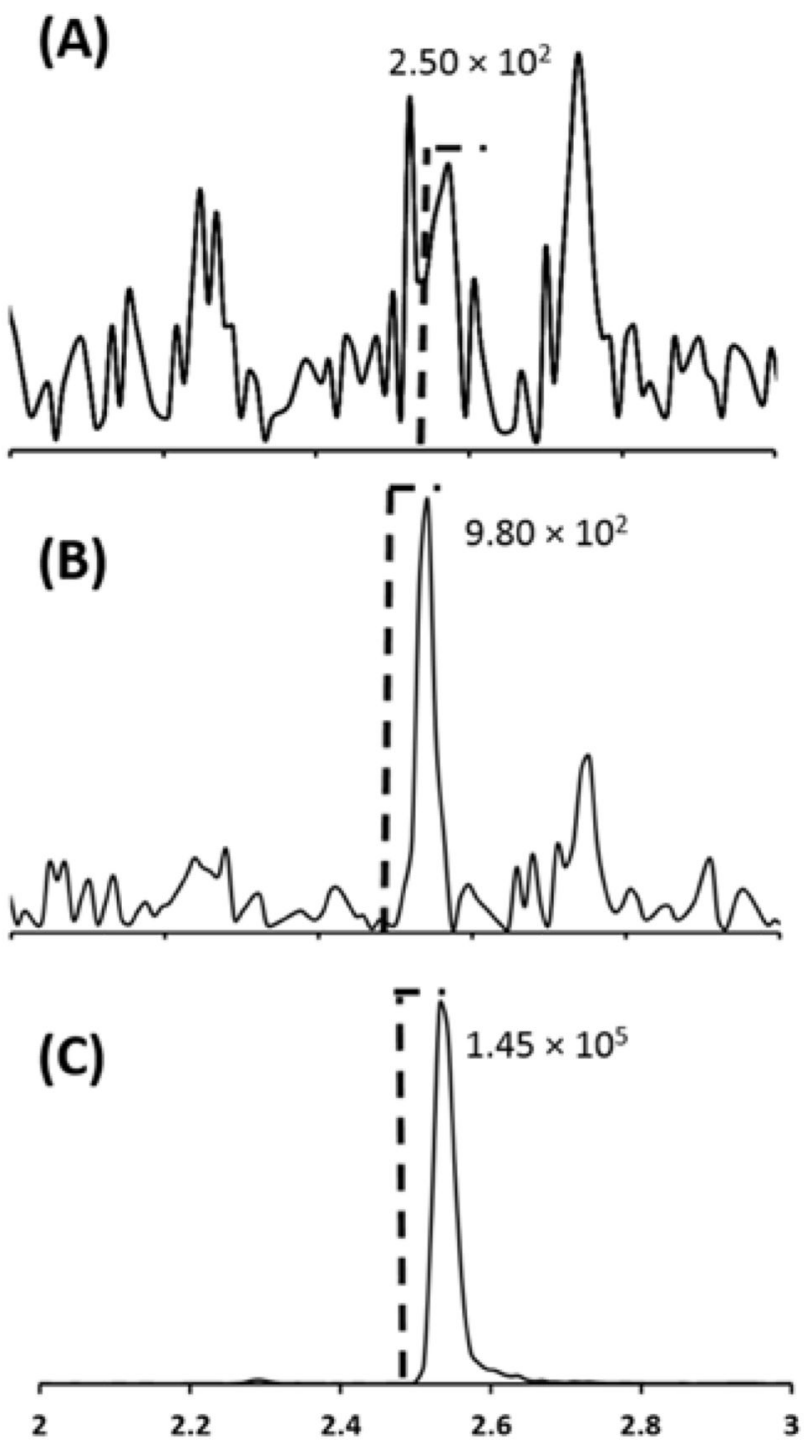
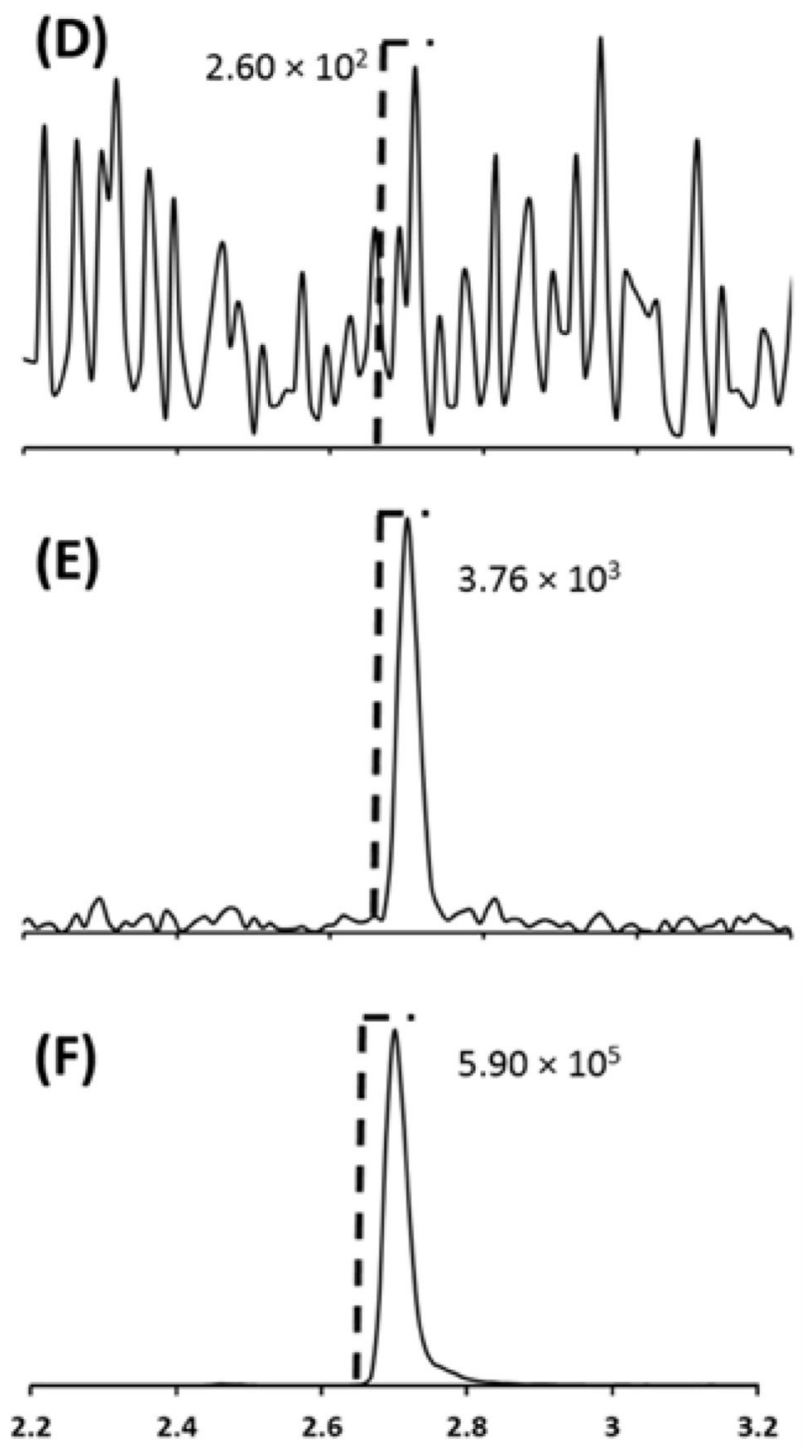

Figure 2.

Extracted ion chromatograms of rambutan extract containing (A) no HGA added, (B) 1.00 ng/mL HGA, (C) 200 ng/mL HGA, (D) no MCPG added, (E) 1.00 ng/mL MCPG, (F) 200 $\mathrm{ng} / \mathrm{mL}$ MCPG. Detection of HGA was based on the transition of dns-HGA $\mathrm{m} / \mathrm{z} 375.1 \rightarrow$ 170.1 (A-C). MCPG used the transition of dns-MCPG $\mathrm{m} / z 361.1 \rightarrow 170.1$ (D-F). The dashed lines indicate the chromatographic peak height. 
MCPG

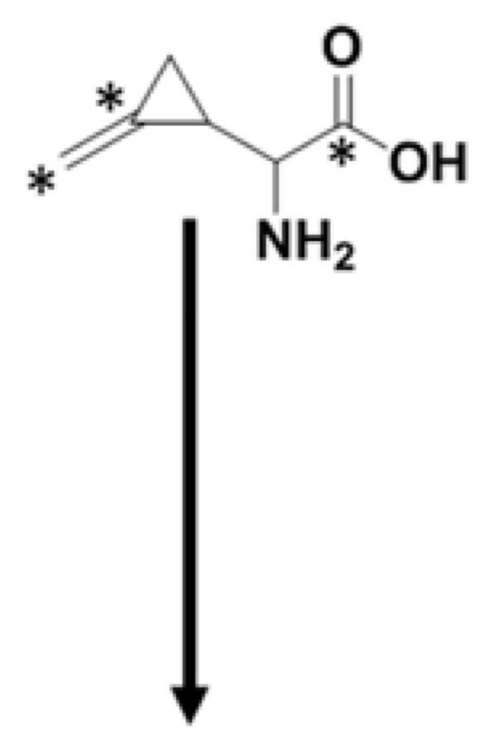

dns-Cl

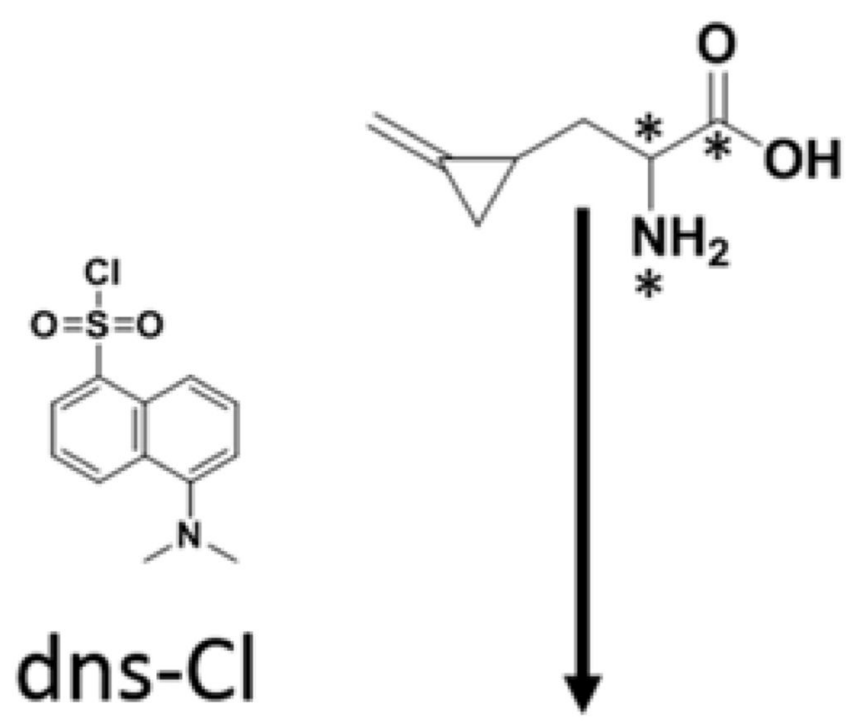

HGA

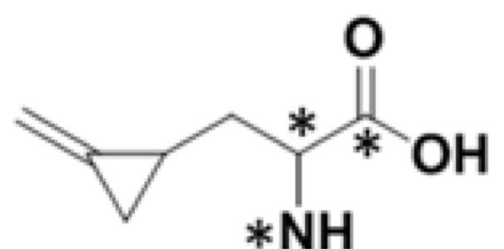

$\mathbf{O}=\mathbf{S}=\mathbf{O}$

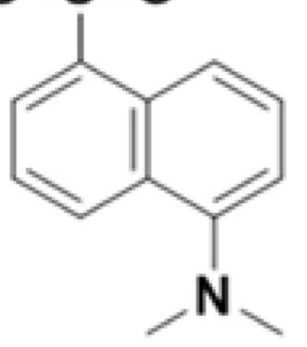

dns-hypoA

Scheme 1.

Derivatization of MCPG and HGA with dansyl chloride (labeled sites of internal standards are represented by asterisks). 


\section{Table 1}

Intra-fruit sampling variability.

\begin{tabular}{ccc}
\hline Fruit Sample $^{*}$ & MCPG $(\boldsymbol{\mu g} / \mathbf{g})$ & HGA $(\boldsymbol{\mu g} / \mathbf{g})$ \\
\hline Biopsied Tissue 1 & 9.73 & 20.2 \\
Biopsied Tissue 2 & 10.6 & 29.6 \\
Biopsied Tissue 3 & 9.77 & 21.7 \\
Biopsied Tissue 4 & 7.89 & 24.0 \\
Biopsied Tissue 5 & 9.75 & 24.9 \\
Biopsied Tissue 6 & 8.91 & 28.0 \\
Pre-homogenized 1 & 8.48 & 25.3 \\
Pre-homogenized 2 & 10.7 & 28.8 \\
\hline Average \pm std dev & $\mathbf{9 . 5 0} \pm \mathbf{0 . 9 9}$ & $\mathbf{2 5 . 3} \pm \mathbf{3 . 4}$ \\
\% RSD & $\mathbf{1 0}$ & $\mathbf{1 3}$ \\
\hline
\end{tabular}

* All samples taken from one single fruit. Pre-homogenized samples consisted of approximately 2 grams of fruit aril. After dehydration, 1.1 to 3.1 mg were processed. 
Table 2

Precision (\% RSD) and accuracy (\% RE) data $(n=22)$ for all calibrators and QCs for HGA and MCPG in rambutan extract.

\begin{tabular}{ccccc}
\hline \multirow{2}{*}{$\begin{array}{c}\text { Concentration } \\
(\mathbf{n g} / \mathbf{m L})\end{array}$} & \multicolumn{2}{c}{ MCPG } & \multicolumn{2}{c}{ HGA } \\
\cline { 2 - 5 } & \% RSD & \% RE & \% RSD & \% RE \\
\hline $\mathbf{1 . 0 0}$ & 15 & -1.3 & 10 & -14 \\
$\mathbf{2 . 0 0}$ & 11 & -1.3 & 10 & -2.0 \\
$\mathbf{5 . 0 0}$ & 7.3 & -1.5 & 6.7 & -1.5 \\
$\mathbf{1 0 . 0}$ & 5.9 & 3.0 & 5.4 & 6.3 \\
$\mathbf{2 0 . 0}$ & 5.0 & -0.23 & 5.5 & 7.0 \\
$\mathbf{5 0 . 0}$ & 4.3 & 1.4 & 4.9 & 6.4 \\
$\mathbf{1 0 0}$ & 3.5 & 0.33 & 3.9 & 1.5 \\
$\mathbf{2 0 0}$ & 2.4 & -0.61 & 2.3 & -3.2 \\
$\mathbf{7 5 . 0}(\mathbf{Q H}, \boldsymbol{\mu g} / \mathbf{g})$ & 8.8 & 1.5 & 8.6 & 3.1 \\
$\mathbf{1 5 . 0}(\mathbf{Q M}, \boldsymbol{\mu g} / \mathbf{g})$ & 6.3 & 5.8 & 7.8 & 13 \\
$\mathbf{3 . 5 0}(\mathbf{Q L}, \boldsymbol{\mu g} / \mathbf{g})$ & 12 & 12 & 7.8 & 6.6 \\
\hline
\end{tabular}


Table 3

Application of the method for the quantification of MCPG and HGA ( $\mu \mathrm{g} / \mathrm{g}$ dried fruit) in soapberry fruit arils.

\begin{tabular}{|c|c|c|}
\hline Fruit & $\operatorname{MCPG}(\mu \mathrm{g} / \mathrm{g})^{*}$ & HGA $(\mu \mathrm{g} / \mathrm{g})^{*}$ \\
\hline Rambutan $(n=5)$ & $<\mathrm{LRL}$ & $<\mathrm{LRL}$ \\
\hline Longan $(n=5)$ & $<\mathrm{LRL}$ & $<\mathrm{LRL}-2.45$ \\
\hline Litchi-Group $1(n=6)$ & $1.64-9.73$ & $5.90-20.2$ \\
\hline Litchi-Group $2(n=6)$ & $<\mathrm{LRL}-2.42$ & $5.14-21.2$ \\
\hline Litchi-Group $3(n=6)$ & $<\mathrm{LRL}$ & $<\mathrm{LRL}-3.35$ \\
\hline Ackee $(n=1)$ & $<\mathrm{LRL}$ & 1.07 \\
\hline Canned Lychee $(n=1)$ & $<\mathrm{LRL}$ & 1.41 \\
\hline Canned Rambutan $(n=1)$ & $<\mathrm{LRL}$ & $<\mathrm{LRL}$ \\
\hline Canned Longan $(n=1)$ & $<\mathrm{LRL}$ & $<\mathrm{LRL}$ \\
\hline Litchi - Technical Assist $(n=6)^{* *}$ & $44.9-220$ & $12.4-152$ \\
\hline
\end{tabular}

